\title{
Strenuous Exercise
}

National Cancer Institute

\section{Source}

National Cancer Institute. Strenuous Exercise. NCI Thesaurus. Code C39773.

20-60 minutes of exercise which elevates your heart rate to $80-90 \%$ of your maximum heart rate performed at least 3-4 times per week. 